Euskal ikerketen aldizkaria | Revue d'études basques |

Revista de estudios vascos | Basque studies review

19 | 2016

Numéro XIX

\title{
Zein da Mauletik Urruñara dagoen hizkuntza distantzia?
}

\section{Gotzon Aurrekoetxea}

\section{OpenEdition}

Journals

Édition électronique

URL : https://journals.openedition.org/lapurdum/3153

DOI : 10.4000/lapurdum.3153

ISSN : 1965-0655

Éditeur

IKER

Édition imprimée

Date de publication : 1 janvier 2016

Pagination : 85-100

ISBN : 978-2-95534-134-6

ISSN : $1273-3830$

Référence électronique

Gotzon Aurrekoetxea, «Zein da Mauletik Urruñara dagoen hizkuntza distantzia?», Lapurdum [Linean] 19 | 2016, Sarean emana----an 01 janvier 2021, kontsultatu 03 septembre 2021. URL: http:// journals.openedition.org/lapurdum/3153 ; DOI: https://doi.org/10.4000/lapurdum.3153 


\title{
Zein da Mauletik Urruñara dagoen hizkuntza distantzia?
}

Gotzon AURREKOETXEA

UPV/EHU

\begin{abstract}
Dialektometriak edo dialektologia kuantitatiboak egingai bihurtu du dialektologiak hasiera beretik bilatzen zuen hizkeren arteko hizkuntza desberdintasunak neurtu eta hizkeren edo dialektoen arteko mugak modu zehatz batean kuantifikatzea. Ekarpena horren erakusle da: Bourciez corpuseko datuak oinarri izanik, eta hizkuntza desberdintasunak neurtzeko izari desberdinak erabiliz, Ipar Euskal Herriko hizkeren arteko distantziak erakusten dira. Erakustaldirako Maule eta Urruña hartu dira adibidetzat eta bien arteko hizkuntza desberdintasunek zein hizkuntza distantzia eragiten duten aztertzen da. Azkenik, erakutsi diren hizkuntza distantzia horiek zein hizkuntza ezaugarrik sortzen dituen azaltzen da.
\end{abstract}

Key Words: Basque language, regional variation, dialectometry

Hitz gakoak: Euskara, bariazio diatopikoa, dialektometria

\section{Sarrera ${ }^{1}$}

Dialektologia tradizionalean maiz eremu dialektalak bereizteko isoglosa mapak egitean informazio gutxi erabili izan da; gehienetan gainerakoak baino garrantzitsuagotzat jo izan diren ezaugarri gutxi batzuekin eraiki izan dira mapak. Hala ere, informazio gutxi denean bide bakarra hori izan arren, ikertzaileak datu-base batean bildutako informako kopuru handiak erabiltzeko aukera duenean baliabide ahaltsuagoak ditu eskura eremu dialektalak zehazteko orduan.

Dialektologia modernoak datu-baseetan egituratutako informazioa aztertzeko tresna berriak sortu ditu, prozedura estatistiko aurreratuak erabiliz. Datu-baseetako informazioa estatistikarekin eta kartografia automatizatuarekin uztartuz hizkuntza geografiari buruzko ikerketek ikaragarri hobetu eta atzineratu dira azken hamarkadetan. Jean Séguyren lehen lanetik (1973) gaur egunera arteko dialektometriaren (aurrerantzean DM) ibilbidea oso

1. Ikerketa hau UPV/EHUko GIU13/23 ikerketa-taldeei emandako diru-laguntzen barnean garatu da. 
oparoa izan da, bidimentsionaletik multidimentsionalera iraganez, cluster mota desberdinetatik DM korrelatibora pasatuz, eskala multidimentsional (Multidimensional Scaling-MDS) eta beste saiakera esperimental batzuk egiteraino, geroago eta teknika sofistikatuagoak erabiliz.

Ekarpen honek teknika zenbait uztartzen ditu herri edo hizkeren arteko hizkuntza distantzia edo desberdintasunak zehazteko, distantzia matrizea erakutsiz eta hizkuntza datuetatik datu numerikoetara iraganez, mapa zenbaitetan pausatu eta gogoeta eginez. Nire esker ona erakutsi nahi diot liburu honekin omentzen dugun Xarlesi, lankide nekaezin bezain abegikor, bere ibilbide zientifikoan gogo izan duen gai bati ekinez, ez baitut ahanzten bera izan zela DM alorrean sartu ninduena eskuratzen zizkidan garai hartan urriak ziren gai honetako artikuluen bidez, duela jada 30 urte baino gehiago.

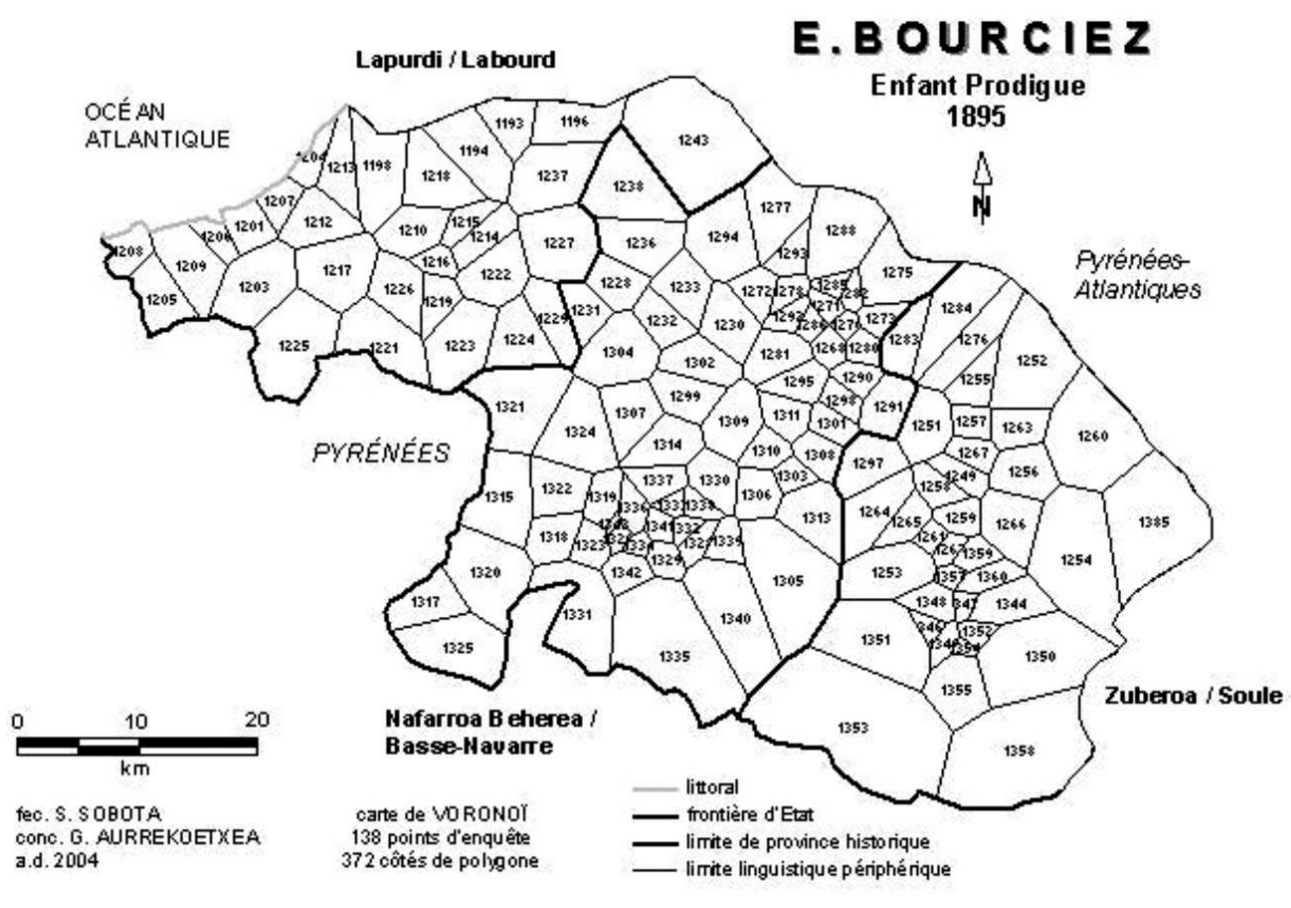

Mapa 1: Bourciez corpusean bildutako herriak (VDM programarekin sortua)

\section{Hizkuntza neurriaren unitatea}

Hizkeren arteko hizkuntza desberdintasunak neurtzeko nagusiki bi unitate erabili izan dira dialektometrian: RIV (Relative Index Value), IRI (índice Relativo de Identidad) bezala ere ezagutua, distantzia eta Levenshtein algoritmoa (aurrerantzean RIV eta LA). RIV distantzia Salzburgoko unibertsitean garatutako dialektometriak erabili izan du eta han sortu den VDM 
programa ${ }^{2}$ informatikoan inplementatuta agertzen da. Distantzia hau distantzia kategorikoa da, nominala; hitzak bere osotasunean konparatzen ditu eta aski da konparatzen diren bi hitzen artean soinu bat desberdin izatea hitzak osoki desberdintzat jotzeko; LA izaria, aldiz, Groningengo DM eskolak ekarri du dialektologiara eta Gabmap programan ${ }^{3}$ inplementatu. LA-k konparatzen diren hitzen arteko soinuetan desberdinak direnak zenbatzen ditu; konparatzen diren bi hitzen artean dauden soinu desberdinak kontatzen ditu eta horietan oinarritzen da desberdintasuna. EUDIA ikerketa-taldeak sortutako Diatech programak ${ }^{4}$ bi izariak inplementatu ditu.

\subsection{RIV neurria}

Ezer baino lehen utz iezadazu irakurle, RIV neurria erabiliz hizkuntza distantzia batzuk erakusten (1. taula) $)^{5}$. Taulan Bourciez corpuseko datuak erabiliz sortutako datu-baseko ezaugarri guztiak kontuan hartuz (lexikoak, fonologikoak, morfologikoak eta sintaktikoak), egindako neurketa batzuk (ez denak)azaltzen dira, ilustrazio gisa. Ahatsatik (1. mapan 1328 puntua) abiatuz, adibidez, distantzia txikiena aski hurbil diren Bunuzera (1303 puntua) eta Izurara (1311) dago (32,11 RIV) eta distantzia handiena 56,91 RIV, hain zuzen ere OzazeZüharara (Zuberoan den 1357 puntua) (ikus 2. mapa).

\begin{tabular}{|l|l|l|}
\hline \multicolumn{3}{|c|}{ Hizkeren arteko RIV distantziak } \\
\hline abiapuntua & Distantzia txikiena & Distantzia handiena \\
\hline Ahatsa & Bunuze eta Izura: 32,11 & Ozaze-Zühara: 56,91 \\
\hline Ahetze & Arrangoitze:22,36 & Altzai: 58,13 \\
\hline Aiherra & Lekorne: 25,20 & Lexantzü eta Altzai: 53,25 \\
\hline Ainharbe & Urdiñarbe: 25,31 & Sara eta Azkarate: 57,55 \\
\hline Armendaritze & Uharte Garazi: 27,24 & Lexantzü: 52,44 \\
\hline Bardoze & Bastida: 21,14 & Altzai: 58,13 \\
\hline Eskiula & Sarrikotapea: 19,51 & Larresoro: 59,35 \\
\hline Etxebarre & Lexantzü: 4,07 & Larresoro: 63,01 \\
\hline Jutsi & Arhantsusi: 22,36 & Lexantzü eta Etxebarre: 51,63 \\
\hline Larresoro & Senpere: 21,95 & Altzürükü: 63,01 \\
\hline Maule & Ürrüstoi: 19,11 & Larresoro: 56,91 \\
\hline Santa Grazi & Aloze: 13,01 & Azkarate: 58,94 \\
\hline Urruña & Azkaine: 25,20 & Lexantzü eta Etxebarre: 62,20 \\
\hline
\end{tabular}

1. Taula: zenbait hizkuntza distantzia RIV neurria erabiliz.

2. http://dialectometry.com/dmdocs/index.html

3. https://www.gabmap.nl/

4. http://eudia.ehu.es/diatech/login/?next=/diatech/index/

5. Taula honetan Hendaia neurketatik kanpo utzi da, herri honetako testuak biltzen dituen berezitasunak direla eta. 
Corpus honetako ezaugarriak erabiliz hizkeren edo herrien arteko hizkuntza RIV distantzia handiena 63,01 da eta Larresorok (1216 puntua 1. mapan) bai Altzürükü (1253), Etxebarre (1349), Lexantzü (1354) eta Mitikile (1263) hizkerekin lortzen dira (ikus 2. mapa).

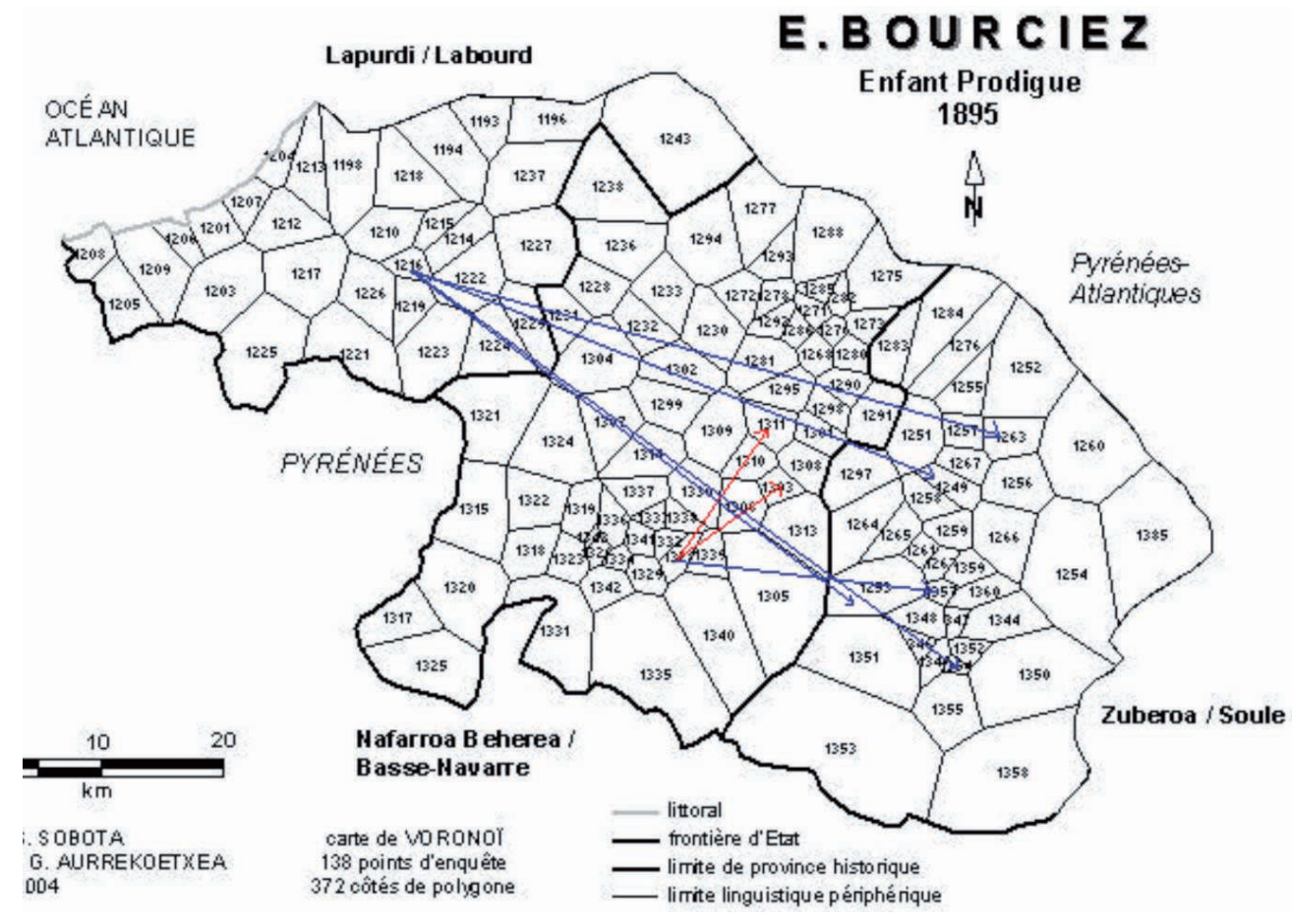

2. mapa: RIV distantziak abiapuntua Ahatsa eta Larresoro izanik.

Bestalde, RIV distantzia txikienak hartzen badira, Etxebarre (1349) eta Lexantzüren (1354) artean kokatzen da txikiena $(4,07)$ eta ondoren Garindaine (1258) eta Urdiñarberen (1265) artean agertzen da, 6,50 delarik; biak Zuberoan lortzen dira, kohesio handiena erakusten duen euskalkia izanik, jada Aurrekoetxeak (2009) azaltzen duen legez.

Nola kontatzen da RIV neurria erabiliz, ostera? Neurri hau Goebl-ek aplikatu zuen DM-n (1981:357-361, 1983: 363-36 eta beste hainbat lanetan)6. Neurri honek hitzak bere osotasunean hartzen ditu (horregatik deitzen da distantzia kategorikoa, diskretua edo 'nominal measurement') eta nahiko da hitzaren zati bat (soinu bat) desberdina izatea bi hitzak zeharo desberdintzat hartzeko.

\subsection{Levenshtein (LA) neurria}

RIV neurria erabili ordez LA erabiltzen bada distantzia desberdinak lortuko dira. LA neurriak konparatzen diren hitzen arteko soinu desberdinak kontatzen ditu eta

6. Neurri honi buruz ikus eskuragarria den Goebl (1992) laneko 436-438 orrialdeak ere. 
desberdintasunak \%etan ematen (Heeringa 2004; Spruit, Heeringa, Nerbonne, 2008: 70-71).

Neurri honek nola kontatzen duen ikusteko hona hemen adibide bat: buru, büü, buu eta bürü aldaerak izanik, eman dezagun lehen bi aldaeren arteko neurria zehaztu nahi dela. Horretarako bi aldaeretan ematen diren soinuen alderaketa egingo dugu (1) adibidean bezala, Hitzak alineatuz, ahal denik eta soinu berdin gehien parekatuz:

$\begin{array}{ccc}\text { buru } & \text { büü } & \text { desberdintasuna } \\ \text { b } & \mathrm{b} & 0 \\ \mathrm{u} & \mathrm{u} & 1 \\ \mathrm{r} & & 1 \\ \mathrm{u} & \ddot{\mathrm{u}} & 1\end{array}$

Beraz, 3/4 desberdintasun (\%75). Bi hitzen arteko desberdintasunen neurria hitzetan diren soinuen arabera egin da, eta desberdinak diren soinuak gehituz lortzen den zenbakia, hitz luzeenak dituen soinu kopuruaren artean zatituz lortzen da neurria. Irakurlea ohartu zatekeenez, desberdintasunak hitz batetik bestera pasatzeko beharrezko diren soinu gehitze, soinu aldatze edo soinu galtzean sortzen dira.

RIV erabiliz bi hitzen arteko distantzia "1" izango litzateke, baina LA erabiliz 0,75; hots, distantzia txikiagoak lortzen dira. RIV neurriekin gorago erabili den taula berrartzen bada eta herri berak atxikiz LA distantziak ezartzen baditugu argi agertuko da distantzia hauek haiek baino txikiagoak direla (ikus 2. taula).

Ahatsa herritik abiatuz LA distantzia txikiena Mendiberekin lortzen da $(19,35)$ eta handiena Ozaze-Zuhara herriarekin $(35,53)$. RIV distantzietan laburrena ez zen lortzen Mendiberekin, Bunuze eta Izurarekin baizik, baina distantzia handiena kasu bietan OzazeZuhararekin lortzen dira. Baina kasu bietan LA distantziak txikiagoak dira RIV distantziak baino. Bourciez corpusean oinarrituz Iparraldeko herrien arteko LA distantzia handiena 44,43 da eta Larresoro eta Lexantzü herrien artean ematen da.

\begin{tabular}{|c|c|c|}
\hline \multicolumn{3}{|c|}{ Hizkeren arteko LA distantziak } \\
\hline Abiapuntua & Distantzia laburrena & Distantzia handiena \\
\hline Ahatsa-1328 & Mendibe: 19,35 & Ozaze-Zuhara: 35,53 \\
\hline Ahetze-1212 & Arrangoitze: 12,36 & Arrokiaga: 35,15 \\
\hline Aiherra-1236 & Donostiri: 15,11 & Donapaleu: 30,90 \\
\hline Ainharbe-1251 & Santa Grazi-1358: 15,0196 & Azkarate: 35,67 \\
\hline Armendaritze-1302 & Uharte Garazi-1326: 14,44 & Arrokiaga: 31,31 \\
\hline Bardoze-1243 & Bastida-1238: 12,5 1 & Arrokiaga: 35,17 \\
\hline Eskiula-1385 & Ürrüstoi-1252: 10,82 & Larresoro: 37,31 \\
\hline Etxebarre-1349 & Lexantzü: 1,52 & Larresoro: 40,05 \\
\hline Jutsi-1308 & Arhantsusi-1301: 13,89, & Larresoro: 34,03 \\
\hline Larresoro-1216 & Senpere: 13,83 & Lexantzü: 44,43 \\
\hline Santa Grazi-1358 & Aloze-1347: 5,95 & Larresoro: 37,20 \\
\hline Urruña-1209 & Biriatu-1205: 15,11 & Lexantzü-Zunharre: 38,06 \\
\hline
\end{tabular}

Taula 2: herrien arteko distantzia numerikoak LA neurria erabiliz 
Aldiz, distantzia laburrena elkarren hurbil diren Zuberoako Etxebarre eta Lexantzüren artekoa da (1,52). Lortu diren RIV eta LA distantzien arteko konparaketa bat agertzen da (2) adibidean, zeinetan herri beren arteko distantzia bi neurrien arabera neurtu den:

$$
\begin{array}{lll}
\text { Etxebarre-Lexantzü distanzia: } & \text { RIV 4,07 } & \text { LA } 1,52 \\
\text { Larresoro-Lexantzü distantzia: } & \text { RIV 63,01 } & \text { LA } 44,43
\end{array}
$$

\subsection{Noiz erabili RIV eta noiz LA neurriak?}

Gorago ikusi bezala RIV eta LA neurriek erabiltzean hizkeren arteko distantzia desberdinak lortzen dira. Neurtzeko izari desberdinak izatea ez da arazo, zehaztasunez neurtzen badute, bederen. Izari sistema asko dago alor desberdinetan: gainazala neurtzeko (metroa, hazbetea, jarda, milla), luzera neurtzeko (sistema metrikoa, amerikarra...), likidoak neurtzeko (litroa, galoia, pinta...), e.a. Gainera, izen bereko izariak lekuen arabera balio desberdina izan lezake. Beraz, edozein gaitan izari desberdinak izatea ez bada arazo, hizkuntzalaritzan ere hizkuntza bariazioa neurtzeko izari desberdinak izatea ere ez da arazo bihurtu behar, eskola eta helburuen araberakoa izan baitaiteke bata ala bestea aukeratzea. Harrigarritzat jo behar da hizkuntza geografia eta hizkuntzaren bariazioa aztertzen gizateriak mende bat baino gehiago eraman arren oraintsu arte ez sortu izana horretarako neurgailu zehatz bat. Jean Séguy ahanztezina izan zen lehena geografiaren araberako hizkuntzaren bariazioa neurtzeko zenbakiak eta izari bat erabili zituena. Horretarako Hamming-en distantzia deitua erabili zuen. Eta dialektologia tradizionalaren markoan lan egiten duten dialektologo batzuk oraindik ere mesfidati diren arren, DM-k urrats sendo eta atzeraezinak eman ditu dagoeneko.

Egun eta hizkeren arteko desberdintasunak modu kuantitatiboz neurtu nahi izaten duten ikertzaileek izari desberdinak dituzte eskuragai. Denetarik ezagunenak RIV eta LA dira. Hauek dira, bestalde, DM egiteko edo hizkeren distantziak kuantitatiboki neurtu eta aztertzeko diren programa informatiko berezietan inplementatuta daudenak. Kontua da noiz erabili daitekeen bata eta noiz bestea. Edo zertarako den ona bata eta zertarako bestea.

\subsubsection{Levenshtein izaria (LA)}

LA soinuen aldaketetan oinarritzen den izaria denez, distantzia fonetikoa neurtzeko da on, izan dadin datu fonetikoekin zein ortografikoekin (gorago ikusi den (1) adibidea, kasu). Halako kasuetan RIV distantzia baino zehatzagoa da, hain zuzen ere aldaketa fonetiko txikiak kontuan hartzen dituelako. Gramatika sortzailearen azterketa tradizionaleko azaleko egitura edo aurkezpeneko datuak edo outputak neurtzeko oso egokia eta gomendagarria da LA izaria. Lexikoan ere erabilgarri da corpusean ageri diren hitzak etimologikoki berdinak diren neurrian.

Aldiz, ez da gomendagarria etimologia desberdina duten hitzekin edo sakoneko egitura desberdina duten ezaugarriekin. Adibide bat esaten ari garena bisualizatzeko: artxo eta bildots hitzen arteko distantzia zein den zehaztu nahi bada eta LA izaria erabiltzen badugu ondoko distantzia genuke (3): 
(3)

$\begin{array}{ccc}\text { Artxo } & \text { bildots } & \text { diferentzia } \\ \mathrm{a} & \mathrm{b} & 1 \\ \mathrm{r} & \mathrm{i} & 1 \\ \mathrm{tx} & \mathrm{l} & 1 \\ & \mathrm{~d} & 1 \\ \mathrm{o} & \mathrm{o} & 0 \\ & \text { ts } & 1\end{array}$

Hots, 5/6 diferentzia (\%83). Baina hasiberria ere konturatuko da bi hitz hauen artean diren berdintasunak menturazkoak edo auzazkoak direla, kasualitate hutsa. Eta ez duela zentzurik honelako hitzak izari honekin neurtzeak, guztiz desberdinak diren bi hitz direlako eta beraien arteko desberdintasuna ezin delako 1.00 baino gutxiago izan.

Beraz, etimologia desberdina duten hitzen edo sakoneko egitura desberdina duten ezaugarri gramatikalen arteko distantzia neurtzean ez du zentzurik distantzia fonetikoa neurtzeak, ezta LA izaria erabiltzeak.

\subsubsection{RIV izaria}

Baina ezaugarri fonologikoak edo gramatika sortzailearen azterketa tradizionaleko sakoneko egitura neurtzeko izari kategoriko edo diskretoa ('nominal measurement' ere deitua) den RIV izaria erabili beharrean gaude. Distantzia honek ez ditu "datuak" edo azaleko egiturako datu fonetikoak edo outputak neurtzen, hizkuntza ezaugarriak baizik. Lexikoan ere erabilgarri da corpusean ageri diren hitzak etimologikoki desberdinak diren neurrian edo datuak edo hitzak lematizatu ondoren konparatu nahi direnean. Maila honetan hizkuntza ezaugarriez edo ezaugarri abstraktoez ari gara; beste hitz batzuekin, hizkuntza sistemari dagozkion ezaugarriez, hizkuntzaz eta ez hizketaren ezaugarriez. Maila honetan ezaugarriok hizkera batek (molde batean zein bestean gauzatuta) badituen ala ez da kontua; horregatik beharrezkoa da erabiltzen den izaria kategorikoa izatea, ez ezaugarriaren barnean diren aldaketak zenbatzen dituen sistema graduala.

\section{Data}

Ikerketa honetan darabiltzagun datuak Bourciez corpusean jasotakoak dira (Aurrekoetxea \& Videgain 2004). Corpus honen ustiaketa geolinguistiko orain artean sakonenak Aurrekoetxea, Videgain \& Iglesias (2007) eta Aurrekoetxea, Videgain \& Iglesias (2008) izan dira: lehenean lexikoari dagozkion mapak argitaratu ziren eta bigarrenean gramatika ezaugarrien mapak; egin dira, halaber beste ustiaketa dialektometrikoak ere (Aurrekoetxea 2010; Aurrekoetxea \& Videgain 2009). DM-rako EUDIA ikerketa-taldeak sortutako Diatech tresnak aukera ederra eskaintzen du hizkera (herri) batetik besterako hizkuntza desberdintasunak (edo hizkuntza distantziak) zenbakitan ipintzeko, datu-baseko distantzien matrize numerikoa deskargatzeko aukera duelako.

Lan honetan RIV izaria erabiliko dugu, Bourciez corpuseko datu lexikalen lemak eta ezaugarri gramatikalak erabiliko direlako. Corpuseko ezaugarri guztiak erabiliko dira, hots 34.638 datu (138 herritako datuak x 251 ezaugarri herriko). DM-rako ez da kopuru handia, egia esan, milioka datuak erabiltzeko prestatuta baitaude sortu diren tresnak. Hala ere, 
euskaraz hizkerak konparatzeko eta hizkeren arteko desberdintasunak aztertzean inoiz erabili den kopuru handiena da, zalantza izpirik gabe.

Hasteko, Maulek (Zuberoaren erdigunean kokatuta) corpus honetako gainerako herriekin dituen hizkuntza desberdintasunak edo distantziak erakutsiko dira (zenbakizko distantzietarako ikus 2. eranskina).
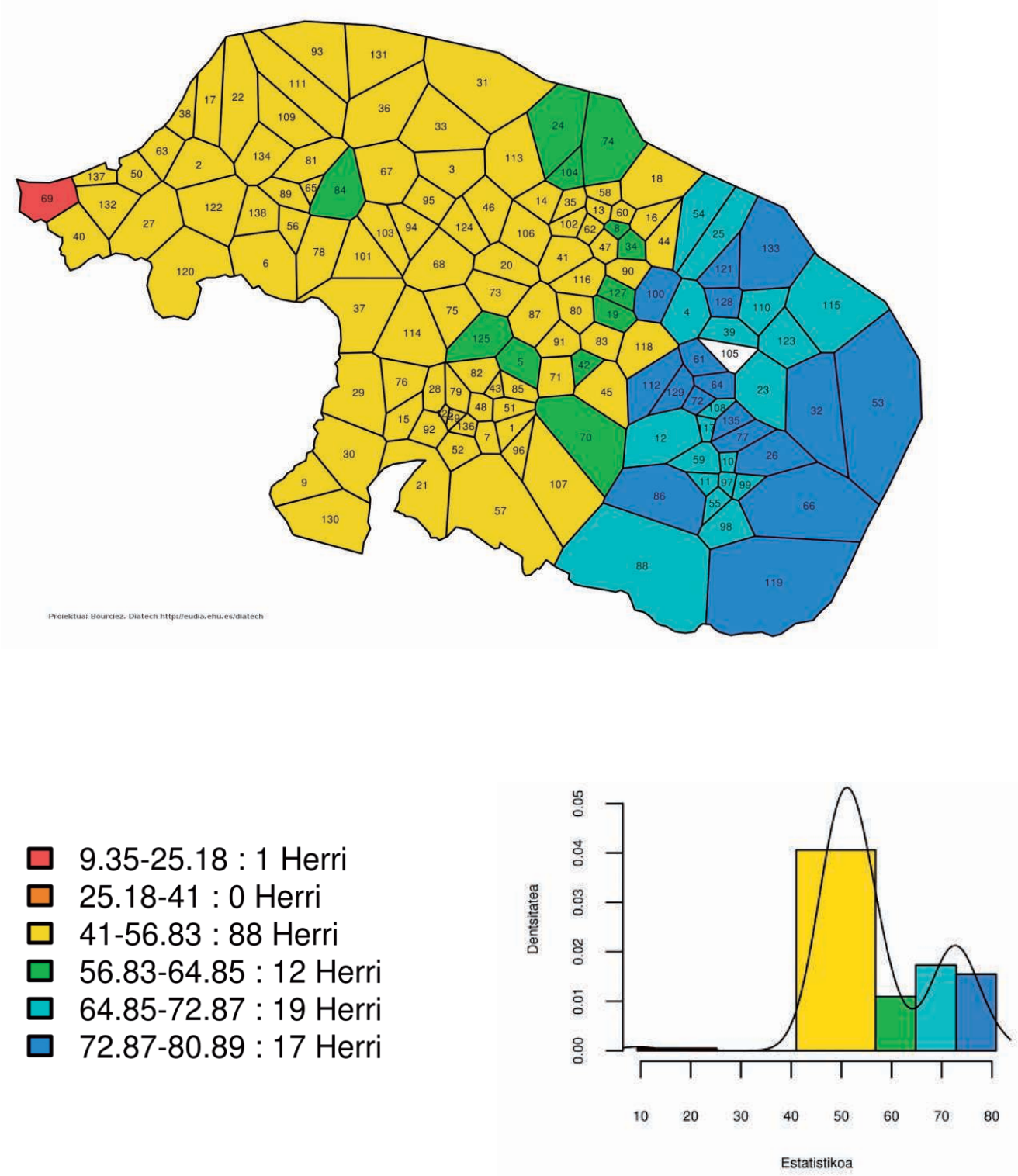

3. Mapa: Mauleren similaritate mapa

Datuak: Bourciez corpusa (251 lan-mapa)

Distantzia izaria: RIV

Bisualizazio algoritmoa: MinMxMax (6 talde) 
3. mapa eraikitzeko Bourciez corpuseko datu guztiak erabili dira. Mapan herri bakoitza poligono baten biltzen da, zeinetan zenbakizko kode bat ezarri zaion; poligono hau erabiltzen da herriari dagokion kolorea ezartzeko. Corpus honetako datuak erabiliz herrien arteko desberdintasunak edo distantziak neurtzean RIV izaria erabili da eta emaitzak 6 multzotan bildu dira (MinMxMax bisualizazio algoritmoa erabiliz): multzo bakoitza desberdintasunen kopuruarekin eta kolore batez adierazten da: kasu honetan urdin ilunak hurbiltasun linguistiko handiena erakusten du eta gorriak txikiena.

Maulek (zuriz agertzen den poligonoa) oso harreman onak ditu Zuberoako gainerako herri guztiekin (urdin ilun eta argiz koloreztatutakoak), Pagola (118 puntua) eta Domintxaine (44 puntua) izan ezik (biak horiz koloreztatuak); antzekotasun kopurua \% 64,85 eta \%80,89 tartean kokatzen da. Gainerako herri guztiak (orlegiz eta horiz margotutako 100 herriak) \%4ltik \%64.85 bitarteko berdintasun edo similaritatea dute Maulerekiko, Hendaia salbu (gorriz). Maule eta gainerako hizkeren arteko distantziak 6 multzotan banandu badira ere MinMxMax algoritmoa erabiliz sortu diren multzoen artean batean ez da herririk (\%25,18tik \%4lrako berdintasuna); hots, berdintasun tarte horretan ez da herririk. Eta 26 herri daude \%50 berdintasun baino gutxiago dutenak Maulerekiko.

Hau guztia datu kopuru handiak datu-base batean egituratzeak dakartzan abantailen adibide bat baino ez da. Baina Diatech tresnak mapa mota asko eraikitzeko aukera ematen die ikertzaileei. Maulek gainerako herriekin dituen berdintasun eta desberdintasunak (edo distantziak) neurtu dira 3. mapan. Ondoko bietan beste abiapuntu batzuk aukeratu dira: Jutsi (4. mapan) eta Heleta (5. mapan); mapa eraikitzeko gainerako zehaztasunak 3 mapa eraikitzeko erabilitakoak dira. Deigarria da oso, Behe Nafarroako ekialdean kokatuta dagoen Jutsi herritik (zuriz margotuta) abiatuz lortzen diren hizkuntza distantzia handienen artean (Hendaia salbu) Zuberoako herri gehienak biltzen direla (Domintxaine -44 puntua- eta Etxarri-54 puntua, izan ezik). Eta horiekin batera, askoz ere logikoagoa dena, mendebaldeko eta erdialdeko herriak. Hurbilen dituen herriak nagusiki Behe Nafarroako ekialdean kokatuta daude eta bere inguruan agertzen dira. Heleta herritik abiatuz (5 mapa), ordea, urrunen diren herriak nagusiki ekialdean (hori eta laranjaz koloreztatuta) kokatuta agertzen dira (Zuberoan eta Behe Nafarroako ipar-ekialdean); eremu horretatik kanpo 6 herri isolatu agertzen dira Lapurdi eta Behe Nafarroan zehar. Bestalde, hizkuntzaz hurbilen dituenak bere inguruan kokatzen dira (urdin ilun eta urdin argiz). Bi mapek erakusten dute distantzia geografikoa eta hizkuntza desberdintasuna ez daudela guztiz lotuta, kasu bietan desberdintasunak ekialderantz handiagoak direlako, Jutsiren kasuan nabarmenago Heletaren kasuan baino, halere. 

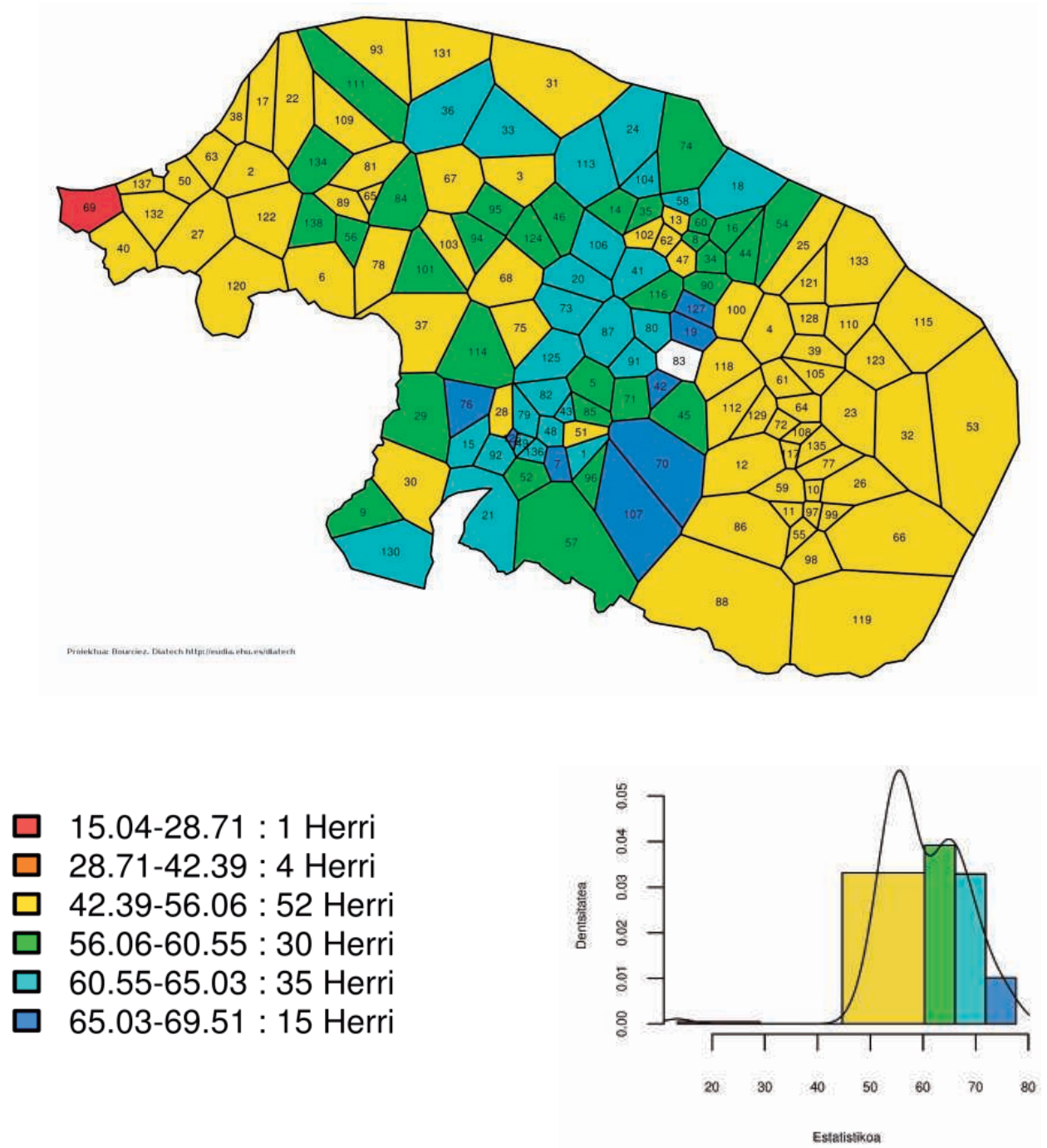

4. Mapa: Jutsitik abiatuz hizkuntza distantziak Datuak: Bourciez corpusa (251 lan-mapa) Distantzia izaria: RIV

Bisualizazio algoritmoa: MinMxMax (6 talde) 


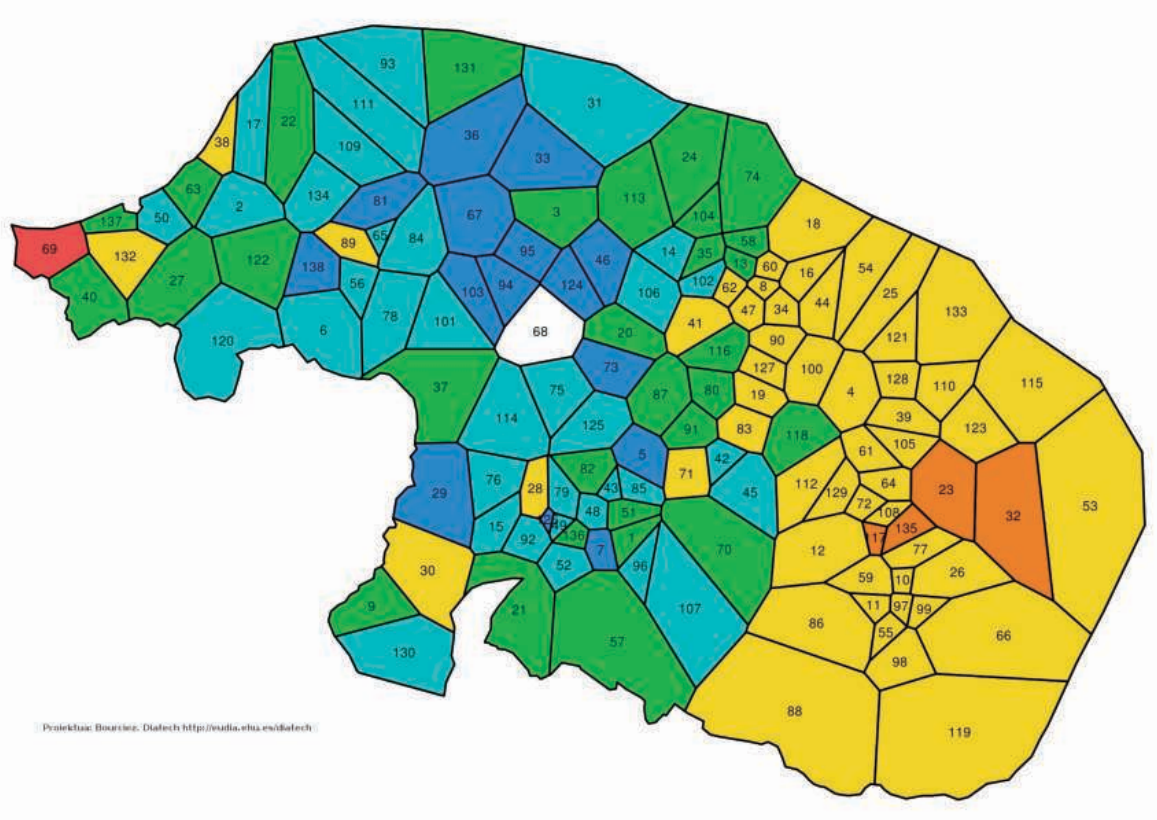

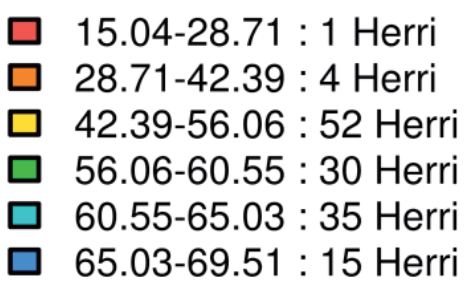

- Mapa: Heletatik abiatuz hizkuntza distantziak

Datuak: Bourciez corpusa (251 lan-mapa)

Distantzia izaria: RIV

Bisualizazio algoritmoa: MinMxMax (6 talde)

Mauleri dagozkion hizkuntza distantzietara itzuliz (3 mapa) eta berdintasunak zenbatu ordez desberdintasunak (oroit 'berdintasunak + desberdintasunak $=100$ ' dela formula) zenbatu egingo ditugu ondoko distantzia taulan (1. taula).

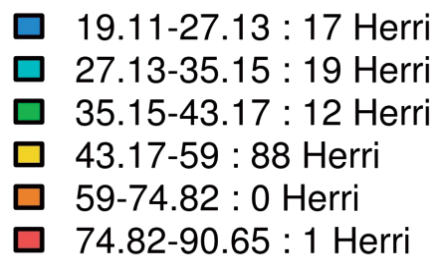

3 taula: hizkuntza distantziak Mauletik 
3 taula eta 3 mapa batera ikusten badira, konturatuko gara horiz margotuta dauden herriak direla distantzia handiena dutenak Maulerekiko (salbu Hendaia). 88 herri dira mapan horiz koloreztatuta daudenak eta tartean da Urruña ere (132 puntua). Herri horien eta Mauleren arteko distantziak \%43.17tik \%59ra bitartean aurkitzen dira. Mauletik Urruñara \%54,88 da hizkuntza desberdintasuna RIV izari edo neurria erabiliz gero. Ez da distantzia handiena, baina inguruko herri askotan agertzen dira antzeko distantziak. Urruñarako hizkuntza distantzia zehaztu den bezala zehatz daiteke corpusean eta datu-basean agertzen diren gainerako herri guztietara ere.

\section{Hizkuntza datuetatik datu numerikoetara eta numerikoetatik hizkuntza datuetara}

Diatech tresnarekin datu-base batean diren hizkuntza datuetatik abiatuz zenbakizko datuetara edo zenbakizko distantzietara bihur daitezke erakutsi den bezala. Baina itzulerako ibilbidea ere egin behar izaten da, zenbakizko distantzia horiek zerk eraginik sortzen diren ikusteko. Azterketa honetan Bourciez corpusa erabili da, zeina 'seme prodigoaren parabola' itzultzean lortutako testuetan oinarrituta dagoen.

Estatistika prozeduretan erabili den datu matrize numerikoa (ikus 1 eranskina) eta Maulek gainerako herriekin dituen hizkuntza desberdintasunak (2 eranskinean) RIV distantzia izariarekin lortutakoak dira. Matrize hauekin azter daiteke zein diren hizkuntza distantzia handiena edo txikienak eta zein herriren artean gertatzen diren, eta herri bakoitzaren hizkuntza distantziak zein diren. Adibidez, Maule izanik abiapuntu hizkuntza distantzia handiena Larresororekin lortu da (\%56,91 desberdintasun); Larresoro (1216 puntua 4 mapan) ez da herri urrunena geografikoki, baina bai hizkuntzari dagokionez. Ondoren agertzen dira Bidarte $(\% 56,50)$ eta Urruña $(\% 54,88)$. Urruña da Mauletik distantzia geografiko handiena duena, baina ez hizkuntza desberdintasun handiena duena.

Zein dira hizkuntza distantzia horiek sortzen dituzten hizkuntza ezaugarriak? Hori aztertzeko aski dugu datu-basera edo hizkuntzari dagokion datu matrizea aztertzea. Maule eta Urruñaren arteko desberdintasun linguistikoa zein ezaugarrik sortu duen jakiteko adibide batzuk ezarriko ditugu (4) bi lerrotan agerraraziz, lehenengoan Mauleko datuak eta bigarrenean Urruñakoak:

$\begin{array}{lll}\text { (4) } \text { gehien } & \text { zaharrena } & \text { 'firstborn' } \\ \text { egun } & \text { gaur } & \text { 'today' } \\ \text { herots } & \text { harrabots } & \text { 'noise' } \\ \text { alor } & \text { landa } & \text { 'field' } \\ \text { argizagi } & \text { ilargi } & \text { 'moon' } \\ \text { ihur } & \text { nihor } & \text { 'anyone' } \\ \text { oro } & \text { guzia(k) } & \text { 'all' } \\ \text { heben } & \text { hemen } & \text { 'here' } \\ \text { hiz } & \text { haiz } & \text { 'you are' } \\ \text { dütie } & \text { dituzte } & \text { 'they have' } \\ \text { (h)un } & \text { (h)on } & \text { 'good' } \\ \text { zanko } & \text { zango } & \text { '(p, t, k) }>(\mathrm{b}, \mathrm{d}, \mathrm{g}) /(\mathrm{n}, \mathrm{l}, \mathrm{r}) \ldots \text { ' }\end{array}$


Lehen bost ezaugarriak lexikoari dagozkio, hurrengo hiruak izen morfologiari, aditz morfologiako bi agertzen dira (hiz vs haiz eta dütie vs dituzte) eta azken biak fonologiari buruzkoak ditugu (ohar bedi irakurlea ezaugarriak lematizatuta daudela, bigarren mailako desberdintasun fonetikoak ezabaturik).

\section{Ondorioak}

Ekarpen honetan erakutsi nahi izan dugu hizkuntza desberdintasunak neur daitezkeela, egokiak diren izariak erabiliz. Horretarako bi izari proposatu dira RIV eta LA: lehena lexikoan etimologia eta gramatikan sakoneko egitura desberdina duten ezaugarriak neurtzeko eta bigarrena azaleko egiturazko datu fonetikoak neurtzeko.

Ondoren, RIV izaria erabiliz, mapa zenbait erabili da herri bat abiapuntu izanik gainerako herrietara dauden hizkuntza distantziak kontatu (datu-matrize numerikoetan) eta marraztu egin dira mapetan. Eta azkenik, Maule eta Urruñaren arteko hizkuntza distantzia sakonago aztertu da, distantzia geografikoarekin parekatuz eta erakutsiz distantzia hori sortu duten hizkuntza ezaugarri batzuk.

Erakutsi dugu ere dialektometriak, eta bereziki Diatech tresnak, bi hizkuntza distantzia neurtzeko izari erabilienak (RIV eta LA) erabiltzeko aukera emanez, herrien arteko hizkuntza desberdintasunak edo distantziak modu zehatzean neurtzeko gaitasuna duela. 


\section{1 eranskina (RIV izariarekin Bourciez corpuseko zenbakizko datu matrizearen zatia)}

\begin{tabular}{|c|c|c|c|c|c|c|c|c|c|c|}
\hline $\begin{array}{l}\text { Ahatsa- } \\
\text { Altzieta...-1 }\end{array}$ & $\begin{array}{c}\text { Ahatsa } \\
-1\end{array}$ & $\begin{array}{c}\text { Ahetze } \\
-2\end{array}$ & $\begin{array}{c}\text { Aiherra } \\
-3\end{array}$ & $\begin{array}{c}\text { Ainharbe } \\
-4\end{array}$ & $\begin{array}{l}\text { Ainhize- } \\
\text { Monj.-5 }\end{array}$ & $\begin{array}{c}\text { Ainhoa } \\
-6\end{array}$ & $\begin{array}{c}\text { Aintzila } \\
-7\end{array}$ & $\begin{array}{c}\text { Aiziritze } \\
-8\end{array}$ & $\begin{array}{c}\text { Aldude } \\
-9\end{array}$ & $\begin{array}{c}\text { Aloze } \\
-10\end{array}$ \\
\hline Ahetze-2 & 45,53 & & & & & & & & & \\
\hline Aiherra-3 & 40,65 & 32,93 & & & & & & & & \\
\hline Ainharbe-4 & 49,80 & 51,43 & 46,53 & & & & & & & \\
\hline Ainhize-Monj.-5 & 39,02 & 32,93 & 34,55 & 46,94 & & & & & & \\
\hline Ainhoa-6 & 43,50 & 25,61 & 30,49 & 50,20 & 33,74 & & & & & \\
\hline Aintzila-7 & 34,96 & 35,77 & 36,99 & 45,71 & 28,86 & 35,37 & & & & \\
\hline Aiziritze-8 & 45,93 & 45,53 & 40,65 & 44,49 & 35,37 & 40,24 & 36,59 & & & \\
\hline Aldude-9 & 44,72 & 30,08 & 35,77 & 51,43 & 40,24 & 32,52 & 34,15 & 41,46 & & \\
\hline Aloze-10 & 54,88 & 55,69 & 51,22 & 31,84 & 47,56 & 54,07 & 50,41 & 45,12 & 58,13 & \\
\hline Altzai-11 & 54,07 & 58,13 & 53,25 & 33,06 & 51,63 & 57,72 & 53,25 & 43,90 & 54,88 & 26,02 \\
\hline Altzürükü-12 & 53,66 & 55,69 & 49,19 & 31,02 & 50,00 & 52,03 & 50,00 & 43,90 & 56,10 & 24,39 \\
\hline Amenduze-13 & 48,78 & 41,87 & 39,43 & 50,20 & 40,65 & 39,84 & 44,31 & 42,68 & 40,24 & 53,66 \\
\hline Amorotze-14 & 39,02 & 39,02 & 37,40 & 48,16 & 32,93 & 39,84 & 31,30 & 39,84 & 39,84 & 51,22 \\
\hline Anhauze-15 & 34,96 & 37,80 & 38,21 & 46,94 & 36,18 & 39,43 & 27,24 & 40,65 & 31,71 & 53,25 \\
\hline $\begin{array}{l}\text { Arberatze- } \\
\text { Zilh.-16 }\end{array}$ & 40,65 & 45,53 & 40,24 & 45,71 & 39,02 & 46,75 & 37,80 & 37,40 & 44,31 & 47,15 \\
\hline Arbona-17 & 50,00 & 32,11 & 38,21 & 53,06 & 36,18 & 34,15 & 42,68 & 47,97 & 41,87 & 57,72 \\
\hline $\begin{array}{l}\text { Arboti- } \\
\text { Zohota-18 }\end{array}$ & 41,87 & 45,12 & 40,24 & 46,94 & 37,80 & 46,34 & 37,80 & 36,18 & 43,09 & 47,15 \\
\hline Arhantsusi-19 & 36,59 & 40,24 & 41,06 & 42,86 & 35,37 & 39,84 & 31,71 & 31,71 & 34,15 & 50,00 \\
\hline Armendaritze-20 & 34,96 & 32,52 & 31,71 & 45,71 & 28,05 & 33,74 & 28,86 & 37,80 & 35,37 & 50,00 \\
\hline Arnegi-21 & 41,87 & 34,55 & 32,93 & 47,76 & 34,96 & 36,59 & 29,27 & 39,02 & 26,42 & 53,66 \\
\hline Arrangoitze-22 & 46,75 & 22,36 & 35,37 & 54,69 & 36,18 & 26,42 & 39,43 & 43,90 & 35,37 & 58,54 \\
\hline Arrokiaga-23 & 53,66 & 57,32 & 49,19 & 33,47 & 53,66 & 56,91 & 50,81 & 43,50 & 54,88 & 33,33 \\
\hline $\begin{array}{l}\text { Arruta- } \\
\text { Sarrikota-24 }\end{array}$ & 39,84 & 39,84 & 36,99 & 43,67 & 33,33 & 40,24 & 35,77 & 34,55 & 41,46 & 44,31 \\
\hline Arüe-25 & 52,03 & 52,44 & 49,59 & 34,69 & 45,53 & 52,85 & 45,53 & 35,77 & 53,25 & 28,05 \\
\hline $\begin{array}{l}\text { Atharratze- } \\
\text { Sor.-26 }\end{array}$ & 50,41 & 48,37 & 47,56 & 29,39 & 41,87 & 48,78 & 44,31 & 40,65 & 52,03 & 26,02 \\
\hline Azkaine-27 & 46,75 & 26,02 & 36,18 & 55,51 & 39,43 & 24,80 & 39,84 & 45,53 & 33,33 & 58,54 \\
\hline Azkarate-28 & 44,72 & 40,24 & 39,43 & 57,55 & 41,06 & 42,28 & 36,18 & 43,50 & 32,11 & 62,60 \\
\hline Baigorri-29 & 38,62 & 37,80 & 36,18 & 47,76 & 31,30 & 38,21 & 28,46 & 41,87 & 38,21 & 52,44 \\
\hline Banka-30 & 42,28 & 39,02 & 35,37 & 53,47 & 42,68 & 40,24 & 38,21 & 45,53 & 36,99 & 59,35 \\
\hline Bardoze-31 & 47,97 & 28,46 & 34,96 & 51,02 & 34,15 & 30,89 & 35,77 & 42,28 & 36,18 & 53,25 \\
\hline Barkoxe-32 & 55,10 & 54,69 & 48,98 & 31,43 & 49,39 & 53,88 & 49,39 & 43,67 & 56,73 & 31,84 \\
\hline Bastida-33 & 41,87 & 32,11 & 33,33 & 46,12 & 34,15 & 29,27 & 31,30 & 39,84 & 32,93 & 52,03 \\
\hline
\end{tabular}


2 eranskina: Bourciez corpuseko hizkuntza distantziak Mauletik RIV erabiliz

\begin{tabular}{|c|c|c|c|c|c|}
\hline Ahatsa & 52,03 & Donapaleu & 53,66 & Lehuntze & 52,44 \\
\hline Ahetze & 47,56 & Donazaharre & 44,31 & Lekorne & 47,56 \\
\hline Aiherra & 45,93 & Donibane-Garazi & 46,75 & Lekuine & 50,81 \\
\hline Ainharbe & 29,80 & Donibane-Lohizune & 47,35 & Lekunberri & 44,72 \\
\hline Ainhize & 38,62 & Duzunaritze & 50,41 & Lexantzü & 28,86 \\
\hline Ainhoa & 49,19 & Eiheralarre & 47,97 & Ligi-Atherei & 27,64 \\
\hline Aintzila & 44,72 & Eskiula & 23,98 & Liginaga & 30,08 \\
\hline Aiziritze & 39,02 & Etxarri & 32,93 & Lohitzüne & 26,02 \\
\hline Aldude & 54,47 & Etxebarre & 27,64 & Luhuso & 50,81 \\
\hline Aloze & 28,86 & Ezpeleta & 48,37 & Lukuze & 50,41 \\
\hline Altzai & 30,89 & Ezterenzubi & 47,15 & Makea & 51,63 \\
\hline Altzürükü & 29,67 & Gabadi & 49,59 & Martxuta & 43,09 \\
\hline Amenduze & 50,41 & Gamere & 28,46 & Mehaine & 49,59 \\
\hline Amorotze & 47,15 & Gamue & 43,50 & Mendibe & 50,00 \\
\hline Anhauze & 45,93 & Garindaine & 26,42 & Mendikota & 30,89 \\
\hline Arberatze & 44,72 & Garruze & 47,35 & Milafanga & 46,75 \\
\hline Arbona & 52,44 & Getaria & 50,00 & Mitikile & 28,05 \\
\hline Arboti-Zohota & 45,53 & Gotaine & 22,36 & Mugerre & 49,59 \\
\hline Arhantsusi & 41,87 & Haltsu & 47,76 & Muskildi & 23,58 \\
\hline Armendaritze & 45,12 & Hauze & 26,42 & Oragarre & 47,56 \\
\hline Arnegi & 47,56 & Hazparne & 53,66 & Ortzaize & 52,44 \\
\hline Arrangoitze & 50,41 & Heleta & 52,44 & Ospitalepea & 32,52 \\
\hline Arrokiaga & 33,74 & Hendaia & 90,65 & Ostankoa & 47,97 \\
\hline Arruta & 41,87 & Hozta & 41,87 & Ozaze & 30,08 \\
\hline Arüe & 28,46 & Ibarrola & 44,31 & Pagola & 49,19 \\
\hline Atharratze & 24,39 & Idauze & 21,95 & Santa-Grazi & 26,02 \\
\hline Azkaine & 53,25 & Iholdi & 50,81 & Sara & 51,43 \\
\hline Azkarate & 56,10 & Ilharre & 42,28 & Sarrikotapea & 19,51 \\
\hline Baigorri & 49,59 & Irisarri & 48,78 & Senpere & 50,00 \\
\hline Banka & 54,88 & Irulegi & 49,19 & Sohüta & 27,24 \\
\hline Bardoze & 48,37 & Iruri & 25,61 & St, Donostiri & 50,81 \\
\hline Barkoxe & 26,53 & Itsasu & 51,63 & Suhuskune & 40,65 \\
\hline Bastida & 47,97 & Izpura & 45,93 & Uharte Garazi & 49,59 \\
\hline Behaskane & 43,09 & Izura & 50,81 & Uharte-hiri & 41,06 \\
\hline Behauze & 47,97 & Jatsu & 54,47 & Ündüreine & 25,20 \\
\hline Beskoitze & 50,00 & Jatsu & 53,66 & Urdiñarbe & 23,98 \\
\hline Bidarrai & 53,66 & Jutsi & 47,56 & Urepel & 44,72 \\
\hline Bidarte & 56,50 & Kanbo & 42,28 & Urketa & 53,66 \\
\hline Bildoze & 27,24 & Lakarra & 48,37 & Urruña & 54,88 \\
\hline Biriatu & 53,25 & Lakarri & 25,20 & Ürrüstoi & 19,11 \\
\hline Bithiriñe & 45,12 & Landibarre & 45,12 & Uztaritze & 52,85 \\
\hline Bunuze & 41,46 & Larraine & 28,05 & Zalgize & 26,83 \\
\hline Buztintze & 48,37 & Larresoro & 56,91 & Zaro & 44,31 \\
\hline Domintxaine & 46,75 & Larribarre & 47,15 & Ziburu & 49,59 \\
\hline Donaixti-Ibarre & 49,19 & Larzabale & 52,03 & Zuraide & 52,03 \\
\hline Donamartiri & 45,93 & Lasa & 49,59 & & \\
\hline
\end{tabular}


100

\section{Erreferentziak}

Aurrekoetxea, Gotzon. 2010. The correlation between morphological, syntactic and phonological variation in the Basque language. In Barry Heselwood \& Clive Upton (arg.), Proceedings of Methods XIII. Papers form the Thirteenth International Conference on Methods in Dialectology, 2008, 207-218. Frankfurt: Peter Lang.

Aurrekoetxea, Gotzon \& Xarles Videgain. 2004. Seme prodigoaren parabola ipar euskal herriko 150 bertsiotan. ASJUren gehigarriak, Bilbo: UPV/EHU Argitalpen Zerbitzua.

Aurrekoetxea, Gotzon \& Xarles Videgain. 2009. Le projet Bourciez: Traitement géolinguistique d'un corpus dialectal de 1895. Dialectologia 2. 81-111.

Aurrekoetxea, Gotzon, Aitor Iglesias \& Xarles Videgain. 2007. Bourciez Bildumako Euskal Atlasa (BBEA-1): 1. Lexikoa. ASJU 38(2). 1-309. (2004) [ed. 2007].

Aurrekoetxea, Gotzon, Aitor Iglesias \& Xarles Videgain. 2008. Bourciez Bildumako Euskal Atlasa (BBEA-2): 2. Gramatika. ASJU 39(1). 1-277. (2005) [ed. 2008].

Goebl, Hans. 1981. Eléments d'analyse dialectométrique (avec application à l'AIS). Revue de linguistique Romane 45. 349-420.

Goebl, Hans. 1983. Parquet polygonal et treillis triangulaire. Les deux versants de la dialectométrie interponctuelle. Revue de linguistique romane 47, 353-412.

Goebl, Hans. 1992. Problèmes et méthodes de la dialectométrie actuelle (avec application à l'AIS). In G. Aurrekoetxea \& X. Videgain (arg.), Nazioarteko dialektologia biltzarra. Agiriak, 429-475. Bilbo: Euskaltzaindia.

Heeringa, Wilbert. 2004. Measuring Dialect Pronunciation Differences using Levenshtein Distance. Ph. Diss., Rijksuniversiteit Groningen.

Spruit, Marco René, Wilbert Heeringa \& John Nerbonne. 2009. Associations among linguistic levels, Lingua 111(11). 1624-1642.

Séguy, Jean. 1973. La dialectométrie dans l'Atlas linguistique de la Gascogne. RLiR 37. 1-24. 